Research Article

\title{
Surrounding Rock Stresses on a Working Face-End Roof under Mining Influence
}

\author{
Kang Wang $\left(\mathbb{D},{ }^{1}\right.$ Xinglong Huang, ${ }^{2,3}$ Haibo Li, ${ }^{2,3}$ Feng Zhang $\mathbb{D}^{1,2,4}$ Jiazhen Li ${ }^{1 D},{ }^{1}$ \\ and Zhijie Zhu $\mathbb{D}^{1,2}$ \\ ${ }^{1}$ Mining Engineering School, Liaoning Technical University, FuXin 123000, China \\ ${ }^{2}$ Engineering Laboratory of Deep Mine Rockburst Disaster Assessment, Jinan 250104, China \\ ${ }^{3}$ Shandong Bureau of Coal Geology, Jinan 250104, China \\ ${ }^{4}$ Department of Mining Engineering, Shanxi Institute of Technology, Yang Quan 045000, China
}

Correspondence should be addressed to Feng Zhang; ln_zns@163.com

Received 9 March 2021; Revised 6 May 2021; Accepted 5 October 2021; Published 10 November 2021

Academic Editor: Quoc-Bao Bui

Copyright (C) 2021 Kang Wang et al. This is an open access article distributed under the Creative Commons Attribution License, which permits unrestricted use, distribution, and reproduction in any medium, provided the original work is properly cited.

The evolution process of the surrounding rock failure mechanism is studied because of spalling and roof fall accidents at the top corner of longwall top coal caving faces affected by mining and the difficulty of moving the advanced end support. Methods are proposed to improve the stability of surrounding rocks at the top corner of the end including cutting at the top corner of the end, reinforcing the anchor cable, changing the stress distribution of surrounding rocks at the top corner of the end, and transferring the stress concentration area of surrounding rocks to the deeper rock. Field observations of the surrounding rocks at the top corner of the 15107 fully mechanized caving face show that the stress value of the surrounding rocks at the corner between the roof of the return airway and the coal wall of the working face is $28.9 \mathrm{MPa}$ when the surrounding rocks are in a stable state without mining. The stress value of surrounding rocks at the top corner of the end is $32.3 \mathrm{MPa}$ when it is affected by mining, which results in spalling and roof fall. The surrounding rocks are in a stable state when the maximum stress of the surrounding rocks at the top corner of the reinforced anchor cable's back-end is $26.1 \mathrm{MPa}$. The results show that cutting of the surrounding rocks at the top corner of the end and the reinforcement of the anchor cable can avoid the spalling and roof fall when the top corner of the end is affected by mining and can ensure that the end support advances and working face moves forward.

\section{Introduction}

The roof of the working face-end area of the longwall top coal caving (LTCC) face is affected by many factors such as the forward movement of the working face and the effect of the abutment pressure during the mining, which makes it more difficult to ensure the stability of the roof of the face-end [1]. In the western part of Turkey, Basarir et al. predicated the stresses around main and tail gates during top coal caving by numerical analysis [2]. In Slovenia, Jeromel et al. studied the multilevel longwall top coal caving process by numerical simulations and in situ measurements during coal excavation at different locations in the Velenje Coal Mine [3]. Zang et al. studied the formation and failure process of the triangle hanging plate at the face-end of LTCC by using theoretical analysis, numerical simulation, and field measurement and analyzed the protective effect of the triangle hanging plate to the weak area [4]. Summarizing studies about the stability of the face-end of LTCC, it is generally believed that instability of the face-end can lead to a lower recovery ratio [5-8]. In recent years, experts such as Wang et al., Liu, and Jin et al. $[9,10,12]$ proposed to use end support to maximize the strength and area of roof control, to reduce the influence of periodic weighting on the roof fracture, and to enhance the adhesion of surrounding rocks at the top corner of the end to control the stability of the end roof. However, these methods only enhance the support strength of external surrounding rocks and the cohesion of near-distance coal at the top corner of the roadway end from the surface and do not change the stress distribution of surrounding rocks and the failure range of 
surrounding rocks with mining from the source. Problems such as support movement and maintenance difficulties caused by spalling and roof falling of the end roof affected by mining still cannot be solved under the existing production and support conditions.

Taking the 15107 working face of Erjing Coal Mine as the engineering background, this paper expounds on the failure mechanism and the evolution process of surrounding rocks at the top corner of a fully mechanized caving face under the influence of mining through theoretical analysis and numerical simulation. We examine changing the original stress distribution of surrounding rocks at the top corner of the end to transfer the stress concentration area of the top corner to the deep and to enhance the antimining disturbance ability of the surrounding rocks at the top corner of the end. Industrial field tests verify the feasibility and rationality of the method.

\section{Evolution Process of the Failure Mechanism of Surrounding Rocks at the Top Corner of the End}

2.1. Engineering Background. The 15107 working face of Erjing Coal Mine is located in the northwest wing of the 15\# coal I mining area and is deeply buried with complex geological structures. The working face adopts top coal caving mining technology for a coal thickness of $5 \mathrm{~m}$ and a mining and caving ratio of 1.083 . The intake and return air roadways are rectangular, and the anchor cable and advanced end support are used to maintain the roof. The existing support methods can basically control the deformation of the roadway roof and two sides. However, the coal wall at the top corner of both ends is loose and unstable because it is affected by the mining of the working face and periodic weighting of the roof. Coal wall bearing capacity of the overlying roof strata is gradually lost. The broken roof and serious subsidence cause spalling and roof fall and difficulty in moving the advanced end support when the working face passes the head and tail of the machine, which will affect the advancing speed of the working face (Figure 1).

2.2. Stress Analysis of Surrounding Rocks at the Top Corner of the End. Lateral pressure of the roadway is biaxially unequal and variable under the influence of mining, especially for geological conditions with deep burial and complex structures. At present, it is impossible to theoretically derive the stress solution of roadway surrounding rocks under the condition of unequal lateral pressure. However, under the assumption that the lateral pressure is equal, the analytical formula of roadway surrounding rock stress is solved according to the elastic-plastic theory. The stress distribution of surrounding rocks and the plastic failure zone are approximately analyzed, along with actual mechanical parameters.

Because the height and width of a roadway are far less than the length of a roadway, the stress calculation of a rectangular roadway is transformed into a plane rectangular strain problem. The analytical formula of surrounding rock stress is obtained by using complex variable function theory and elastic-plastic mechanics theory with and without support [11-17].

According to the complex variable function method, the expression of the stress value of roadway surrounding rocks under the plane strain problem is

$$
U=\operatorname{Re}\left[\bar{z} \Phi(z)+\int \psi(z) \mathrm{d} z\right]
$$

In the formula, $\Phi(z)$ and $\Psi(z)$ are two analytic functions of complex variable $z=x+i y$. Re represents the real part of the complex number, $z$ is the complex sum of the complex variable $Z$, and $U$ is the Airy stress function.

2.2.1. The Surrounding Rock Stress of the Roadway Is Not Subject to Support Resistance. The roadway's external surrounding rocks in the direction of $\alpha$-angle with the $x$-axis are subjected to uniform pressure $p$, and the roadway's internal surface is not stressed. As shown in Figure 2, the stress of the external surrounding rocks is consistent, which meets the following relationship:

$$
\left\{\begin{array}{l}
\bar{X}=\bar{Y}=X=Y=0, \sigma_{1}=p, \sigma_{2}=0, \\
B=\frac{1}{4}\left(\sigma_{1}+\sigma_{2}\right)=\frac{p}{4}, \\
B^{\prime}+i C^{\prime}=-\frac{1}{2}\left(\sigma_{1}-\sigma_{2}\right) e^{-2 i \alpha}=-\frac{p}{2} e^{-2 i \alpha}, \\
B^{\prime}-i C^{\prime}=-\frac{p}{2} e^{-2 i \alpha},
\end{array}\right.
$$

where $p$ denotes the stress of surrounding rocks, $X$ is the surface force in the $x$-direction of the roadway, and $Y$ is the surface force in the $y$-direction of the roadway. $\sigma_{\theta}+\sigma_{\gamma}=4 \operatorname{Re} \Phi(\xi)$ is the stress value of the roadway side; in the roadway side, $\sigma_{\gamma}=0$ and $\sigma_{\theta}=\xi=\cos \theta+i \sin \theta$ after simplification can be obtained.

Assume surrounding rock stress of the roadway without support resistance is $\sigma_{\theta}^{\prime}$. 


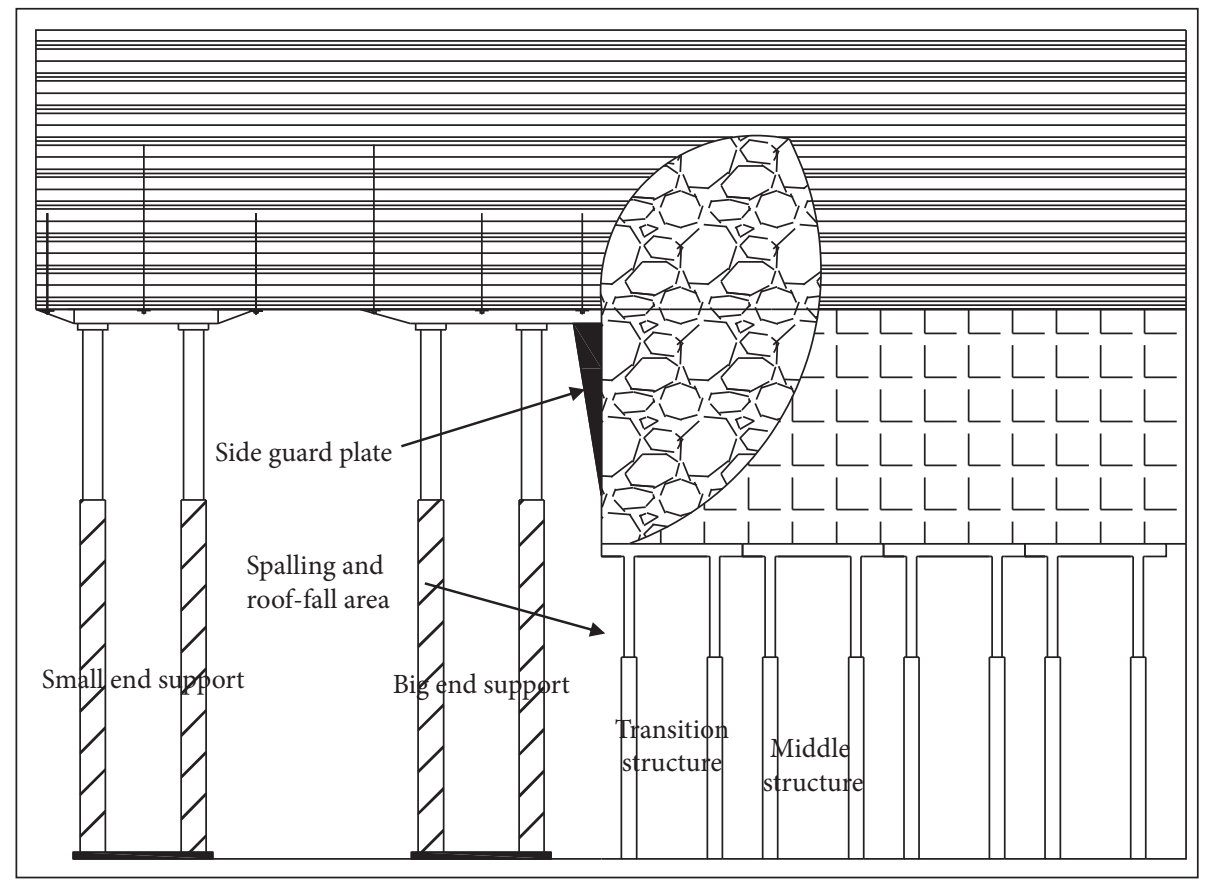

Figure 1: Spalling and roof fall area.

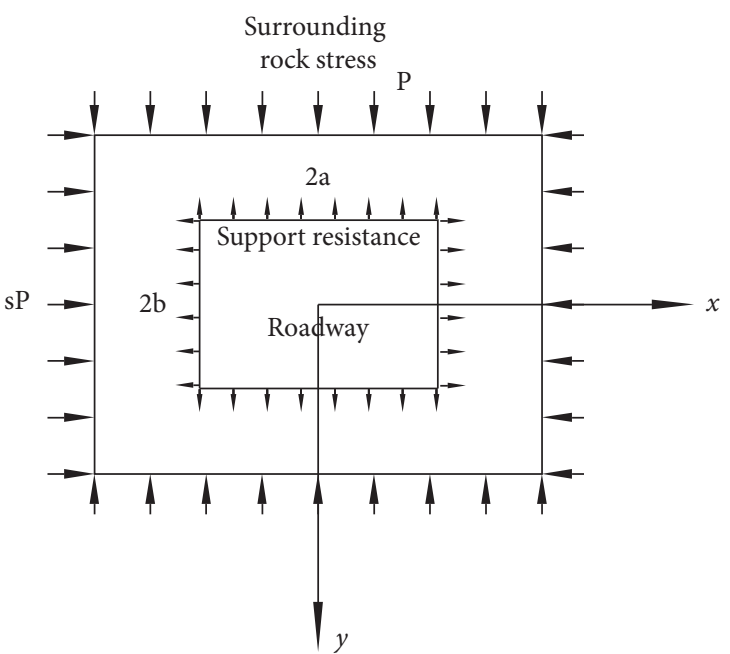

Figure 2: The mechanical model of rectangular roadway analysis.

where $c_{0}, c_{1}$, and $c_{2}$ represent three coefficients of the mapping function, $\mu$ denotes the strain constant, $s$ is the lateral pressure coefficient of the roadway, and $\theta$ is the angle.
2.2.2. The Stress of the Roadway Surrounding Rocks Is Only Subject to Support Resistance. The surrounding rocks of the roadway are only supported by the resistance provided by the support body. The support resistance is uniformly distributed, and the roadway surface is not subjected to any shear force. The internal support resistance is shown in Figure 2, which meets the following relationship:

$$
\left\{\begin{array}{l}
\bar{X}=\bar{Y}=X=Y=0, \sigma_{1}=p, \sigma_{2}=0, \\
B=\frac{1}{4}\left(\sigma_{1}+\sigma_{2}\right)=0, \\
B \prime+i C \prime=-\frac{1}{2}\left(\sigma_{1}-\sigma_{2}\right) e^{-2 i \alpha}=0, \\
B \prime-i C \prime=0 .
\end{array}\right.
$$

Because $\sigma_{\theta}+\sigma_{\gamma}=4 \operatorname{Re} \Phi(\xi), \sigma_{\gamma}=0$.

Assume surrounding rock stress of the roadway without support resistance is $\sigma_{\theta}^{\prime}$.

$\sigma_{\theta}^{\prime \prime}=\frac{[(1+\mu) X / 8 \pi \cos \theta-(1+\mu) Y / 8 \pi \sin \theta+G \cos 2 \theta-F \sin 2 \theta]\left[3 c_{2} \cos 4 \theta+c_{1} \cos 2 \theta-2 c_{0}\right]}{9 c_{2}{ }^{2}+c_{1}{ }^{2}+4 c_{0}{ }^{2}+6 c_{1} c_{2}-12 c_{0} c_{2} \cos 4 \theta-4 c_{0} c_{2} \cos 2 \theta}+\frac{4[(1+\mu) X / 8 \pi \sin \theta-(1+\mu) Y / 8 \pi \cos \theta+G \sin 2 \theta+F \cos 2 \theta]\left[3 c_{2} \sin 4 \theta+c_{1} \sin 2 \theta\right]}{9 c_{2}{ }^{2}+c_{1}{ }^{2}+4 c_{0}{ }^{2}+6 c_{1} c_{2}-12 c_{0} c_{2} \cos 4 \theta-4 c_{0} c_{2} \cos 2 \theta}$.

From the derivation of (3) and (5), it can be concluded that the stress calculation formula of the roadway under the combined action of surrounding rock stress $\sigma_{\theta} \prime \prime \prime$ is

$$
\sigma_{\theta}^{\prime \prime}=\sigma_{\theta}^{\prime}+\sigma_{\theta}^{\prime \prime}
$$

Since the pressure measurement coefficient of roadway surrounding rocks of the adjacent 15105 working face is 0.4 , 
the pressure measurement coefficient of the 15107 fully mechanized caving face is 0.4 using the engineering analogy method. Combined with the geological data of the 15107 fully mechanized caving face, Mathcad 14 software [18] is used to analyze the overall assignment using formula (6) and illustrated in Figure 3.

The stress concentration area of roadway surrounding rocks mainly exists in the top and bottom corners of the roadway, as shown in Figure 3, and the stress value reaches the maximum at the top and bottom corners, which is close to $30 \mathrm{MPa}$. The roadway is in a temporary stable state.

As shown in Figure 4, when the vertical stress $Y$ is constant, with the increase of lateral pressure coefficient $s$, the horizontal stress $X$ increases, and the stress at the top corner of the end increases gradually. When the horizontal stress $X$ is constant, the vertical stress $Y$ increases with the decrease of the lateral pressure coefficient $s$, and the stress at the top corner of the end decreases gradually. According to the above analysis, the roadway stress is mainly affected by the lateral pressure coefficient $s$. When the geological and mining conditions are certain, the lateral pressure coefficient $s$ is mainly affected by mining disturbance.

When the end of the working face is disturbed by mining, the stress $\sigma_{\theta}$ at the top corner of the two ends is several times of that under static pressure, and the top corner stress $\sigma_{\theta}$ increases with the decrease of the distance between the shearer and the end. When the shearer continues to cut coal in the direction of the end and the surrounding rocks' stress $\sigma_{\theta}$ at the top corner of the end reaches a certain critical value, the roof begins to loosen, becomes less stable, and shows fracture failure, and spalling and roof fall accidents occur.

\subsection{Numerical Simulation of the Failure Evolution Process of} Surrounding Rocks at the Top Corner of the End. FLAC3D was used to simulate the variation of stress in the plastic zone of surrounding rocks at the top corner of the 15107 fully mechanized caving face before and after mining [19-29]. The buried depth of the coal seam is $740 \mathrm{~m}$, the model size is $80 \mathrm{~m} \times 50 \mathrm{~m} \times 60 \mathrm{~m}$, the overlying load is $18.5 \mathrm{MPa}$, and the horizontal stress is 7.4 MPa. The basic parameters of rock mechanics are shown in Table 1.

Figure 5 illustrates two stress states and plastic zone distribution characteristics of surrounding rocks. The stress concentration area of the roadway surrounding rock is at the top and bottom corner when the working face is not mined. The top corner stress has reached $27.5 \mathrm{MPa}$. The stress is balanced at the four corners of the roadway, the plastic zone has a butterfly distribution, and the roadway is in a stable state.

The top corner stress of the roadway increases from 27.5 MPa to 36.6 MPa in a stable state when the working face is mined. The stress concentration area has narrowed, the surrounding rock has formed shear failure, and the coal body is less stable at the top corner of the end. It is concluded that the rib spalling and roof caving have appeared at the top corner of the end, and the surrounding rock is in an unstable state.

\section{Control Scheme of Surrounding Rocks at the Top Corner of the End}

3.1. Control Scheme. When spalling and roof fall appear at the end of a fully mechanized caving face, normally, the failure mechanism of surrounding rocks is mitigated by cutting the coal wall near the top corner of the working face. The original stress distribution is changed at the top corner of the end so that the stress concentration area in the surrounding rocks is released at the top corner of the end, and the stress concentration area at the top corner of the end is transferred to the deeper rock. After cutting, the top is supplemented with an anchor cable to strengthen the support strength at the top corner of the end and reduce the probability of coal wall roof instability. Spalling and roof fall accidents must be reduced to ensure the movement of the advanced end support and the mining of the working face.

For the anchor machine to work smoothly after cutting, the wind pick is used to cut at $1 \mathrm{~m}$ from the roof, and the width and height are $1 \mathrm{~m}$. After cutting, adding the metal mesh, and patching the anchor cable $(\varphi 17.8 \mathrm{~mm} \times 8300 \mathrm{~mm})$ to strengthen support, anchor cable spacing is $0.5 \mathrm{~m}$, row spacing is $1 \mathrm{~m}$, each row is $2 \mathrm{~m}$, and square gasket is $250 \mathrm{~mm} \times 250 \mathrm{~mm}$. When cutting once a day, each cutting length is $4 \mathrm{~m}$ to ensure a day of production cycle progress as shown in Figure 6.

3.2. Simulation Test of the Control Scheme. FLAC3D was used to simulate the stress change of the plastic zone of surrounding rocks of the 15107 fully mechanized caving face when it was mined after cutting and reinforcing anchor cables, as shown in Figure 7.

Figure 7 illustrates that when the original stress concentration area of the surrounding rock at the top corner of the end of the air return cross-heading is released, stress concentration area is transferred to the deep part of the top corner of the end, and the maximum stress value at the top corner of the end is also maintained at $27.5 \mathrm{MPa}$ in a stable state. Under the conditions of Figure 7, there is no plastic failure in the surrounding rocks at the top corner, and there are no spalling or roof fall accidents, so the working face can move forward normally.

\section{Field Test}

The KSE-II-1 borehole stress meter was used to arrange two monitoring stations along the top corner of the return air roadway in the 15107 fully mechanized caving face. Three measuring points were arranged in each monitoring station, as shown in Figure 8. Measuring point 1 was $0.5 \mathrm{~m}$ from the exposed coal wall of the top corner with an elevation angle of $30^{\circ}$. The distance between measuring point 2 and measuring point 1 was $1 \mathrm{~m}$, and the distance between measuring point 2 and measuring point 3 was $2 \mathrm{~m}$. The first monitoring station is set at $20 \mathrm{~m}$ in front of the working face to monitor the stress change of the surrounding rock at the top corner of the end. The second monitoring station is set at $50 \mathrm{~m}$ in front of the working face, which is used to monitor the change of the 


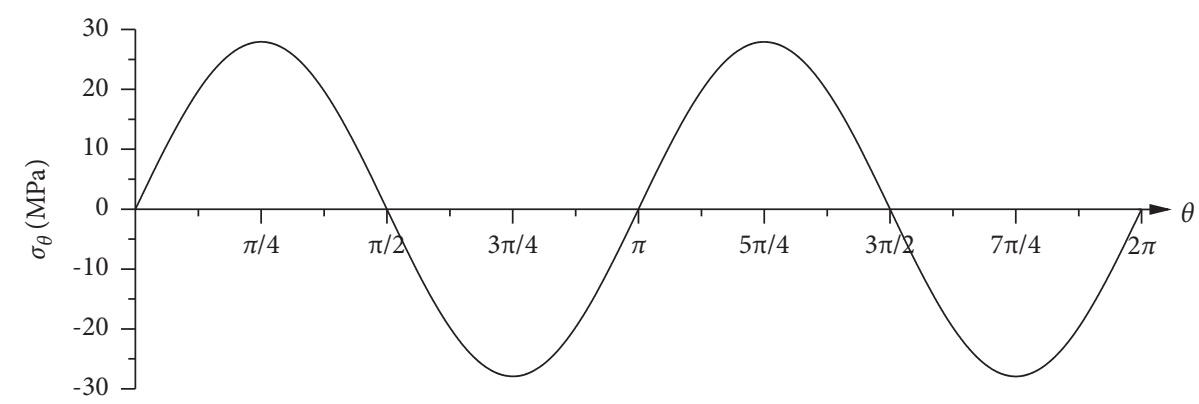

FIGURE 3: Stress distribution of the roadway.

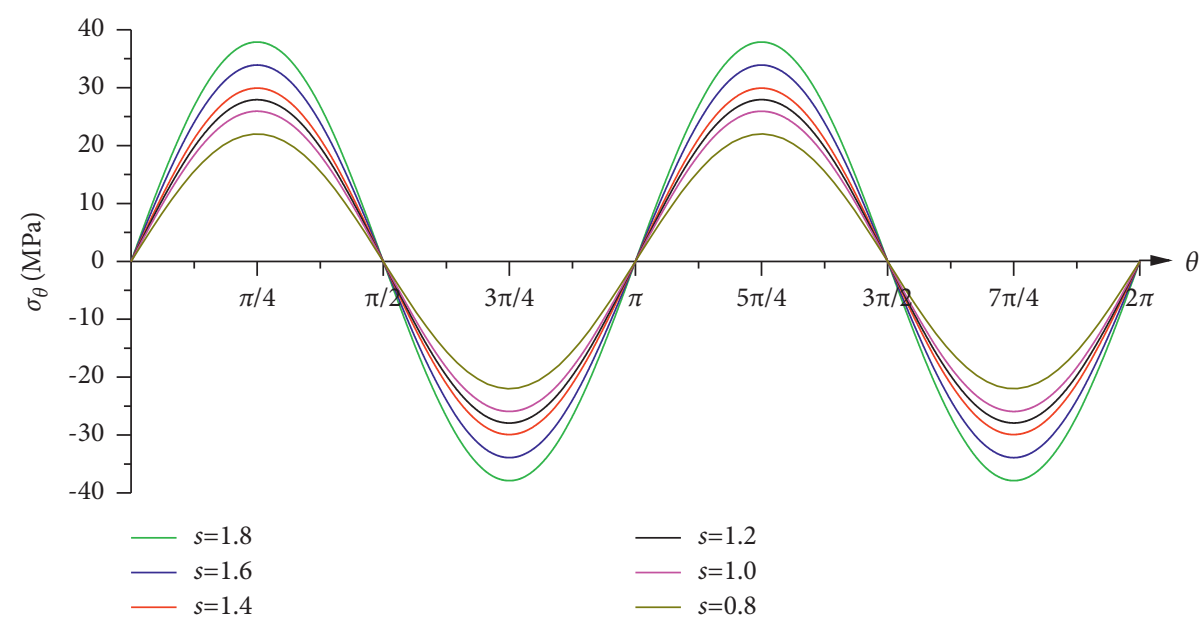

Figure 4: The stress distribution of the roadway with the change of lateral pressure coefficient.

TABLE 1: Basic parameters of rock mechanics.

\begin{tabular}{|c|c|c|c|c|c|c|}
\hline Lithology & $\begin{array}{c}\text { Internal friction } \\
\text { angle }\left({ }^{\circ}\right)\end{array}$ & Cohesion (MPa) & Tensile strength $(\mathrm{MPa})$ & $\begin{array}{c}\text { Elastic } \\
\text { modulus } \\
(\mathrm{GPa})\end{array}$ & Poisson's ratio $(\mu)$ & Density $\left(\mathrm{kg} \cdot \mathrm{m}^{-3}\right)$ \\
\hline Mudstone & 33.0 & 4.50 & 0.93 & 6.20 & 0.12 & 2597 \\
\hline Sandy shale & 33.6 & 10.08 & 1.03 & 3.00 & 0.15 & 2577 \\
\hline Shale & 33.4 & 10.11 & 1.20 & 10.60 & 0.11 & 2653 \\
\hline Limestone & 36.0 & 12.32 & 3.41 & 23.60 & 0.12 & 2682 \\
\hline Coal & 29.5 & 2.11 & 2.60 & 4.20 & 0.22 & 1420 \\
\hline Fine sandstone & 33.4 & 10.12 & 1.95 & 18.60 & 0.21 & 2582 \\
\hline Sandy mudstone & 33.0 & 4.50 & 0.93 & 6.20 & 0.12 & 2597 \\
\hline Mudstone & 33.0 & 4.26 & 1.05 & 5.00 & 0.26 & 2753 \\
\hline
\end{tabular}

top corner stress of the end when it is not mined and when it is mined after cutting and reinforcing anchor cables.

Observations from two monitoring stations are calculated and summarized in previous research. The stress changes of the same measuring point in different measuring points and different states were compared and analyzed, and the stress changes of the same measuring point under the influence of mining were compared and analyzed.

(1) The stresses of the surrounding rock at measuring points 1, 2, and 3 of the first monitoring station were compared and analyzed when the working face was not mined, mined, and mined after cutting and reinforcing with anchor cables, as shown in Figure 9.

(i) Figure 9(a) illustrates that measuring points are affected by the original rock stress at the top corner of the end. The maximum stress value is 28.9 $\mathrm{MPa}$, the stress is relatively concentrated, and there are no spalling and roof fall. When it is mined, the surrounding rock stress concentration area at the top corner of the end is released. Surrounding rock stress value is very low, but spalling and roof fall accidents may occur. 

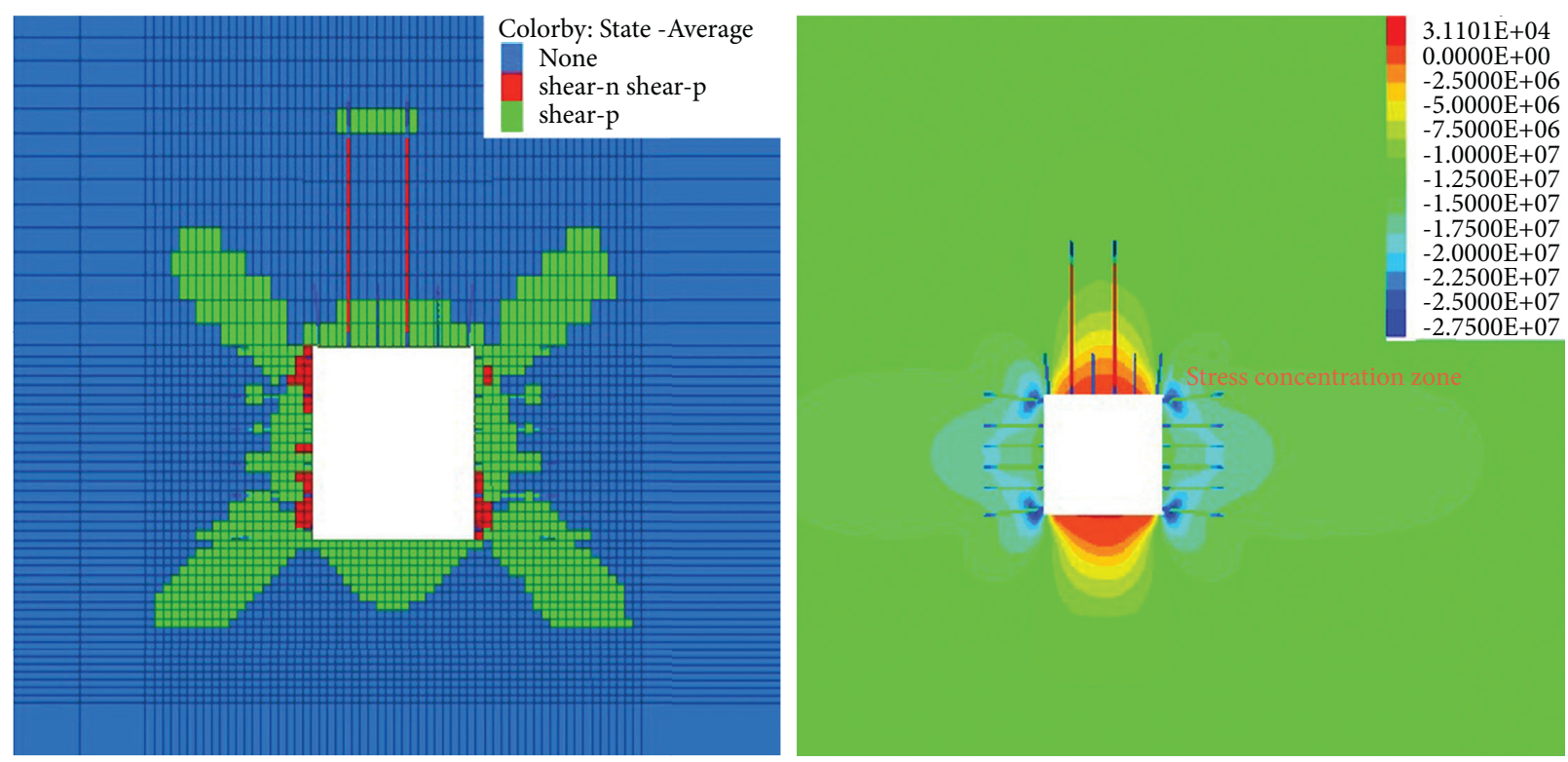

(a)
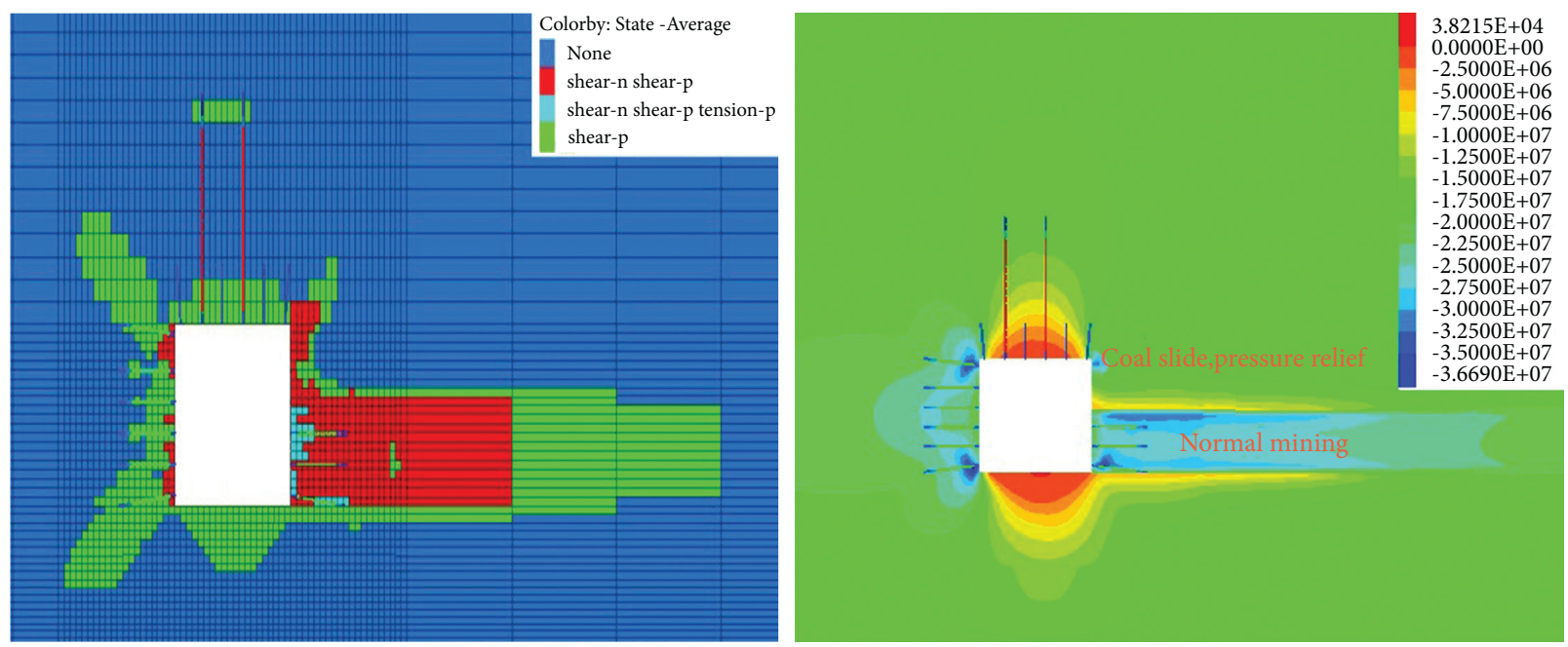

(b)

FIGURE 5: Distribution of the plastic zone and stress of surrounding rocks at the top corner of the end before and after mining: (a) stress distribution of roadway surrounding rocks without mining; (b) stress distribution of roadway surrounding rocks after mining.

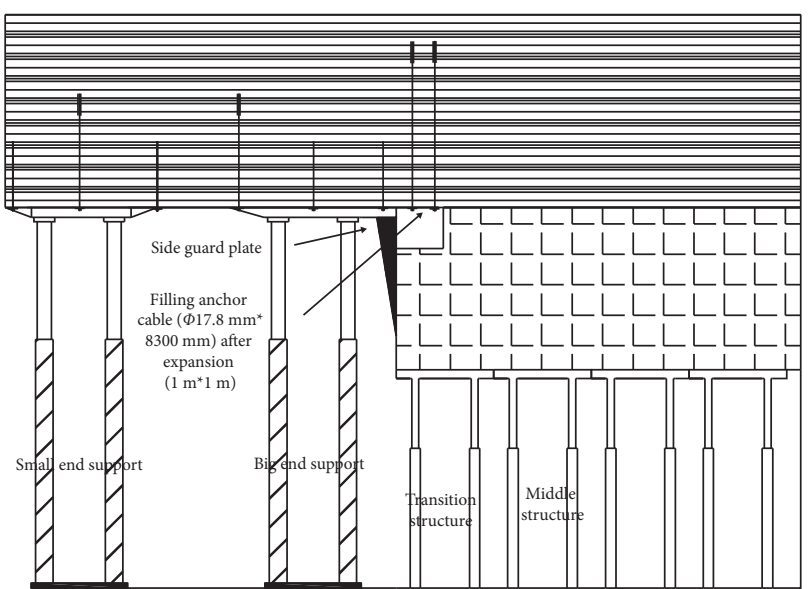

FIgure 6: Cutting the repair cable.
When it is mined after cutting and reinforcing with an anchor cable, the surrounding rock stress at the top corner of the end has been released, the stress value is low, and the surrounding rock tends to be stable.

(ii) Figure 9(b) shows that when the rock face is not mined, the stress value of measuring point 2 is $32.5 \mathrm{MPa}$ at the top corner of the end, and the coal wall is loose, unstable, and wrapped by the external coal body, which is temporarily in a stable state. When it is mined, the stress value is 38.3 $\mathrm{MPa}$ at the top corner of the end, so coal loses stability, and spalling and roof caving occur. After the reinforcement of the anchor cable by cutting, the stress at measuring point 2 is released, the stress concentration area is 

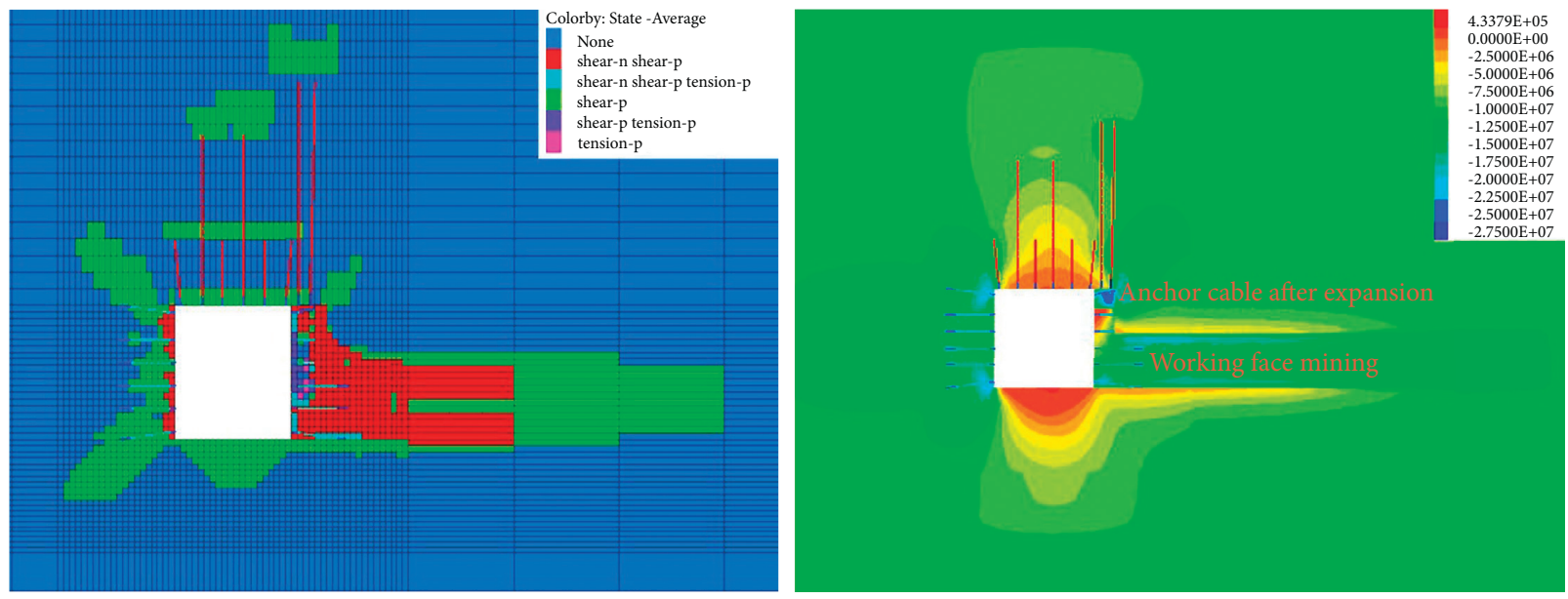

Figure 7: Distribution of the plastic zone and stress at the top corner of the end during mining after cutting and reinforcing anchor cables.

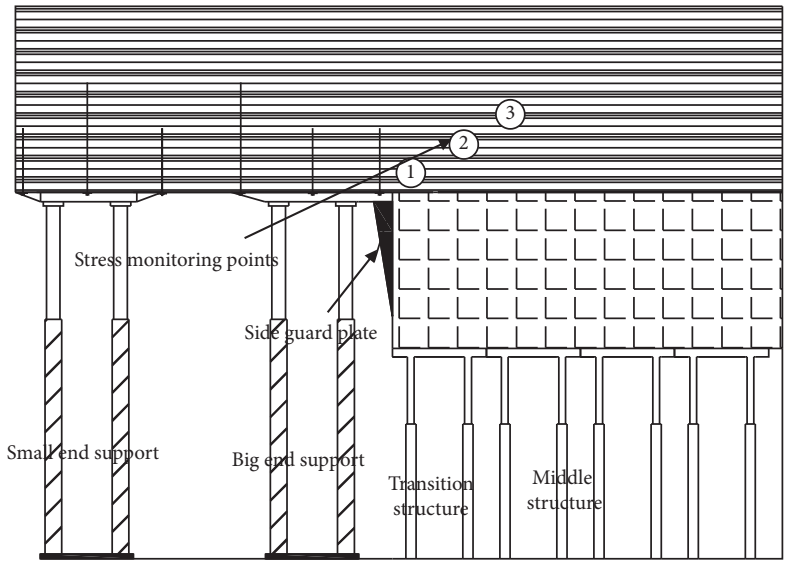

Figure 8: Distribution of measuring points.
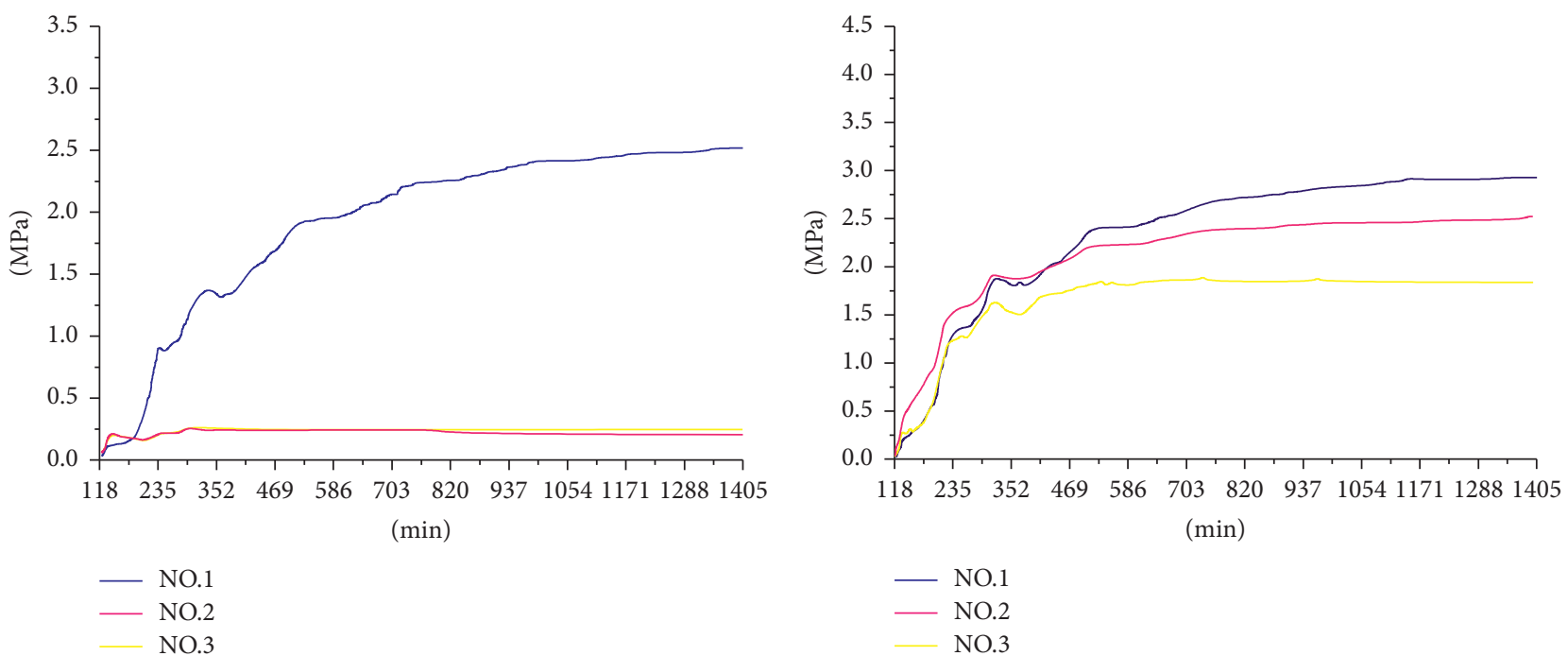

(a)

(b)

FIgURE 9: Continued. 


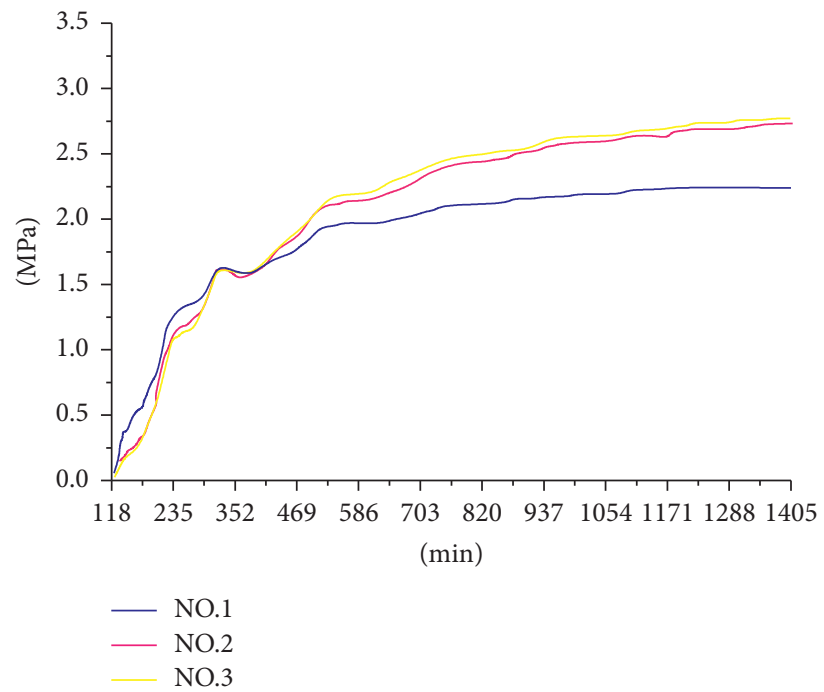

(c)

FIGURE 9: Stress curves of three measuring points at the top corner of the end under three conditions: (a) stress variation curves of measuring point 1 under three states; (b) stress variation curves of measuring point 2 under three states; (c) stress variation curves of measuring point 3 under three states

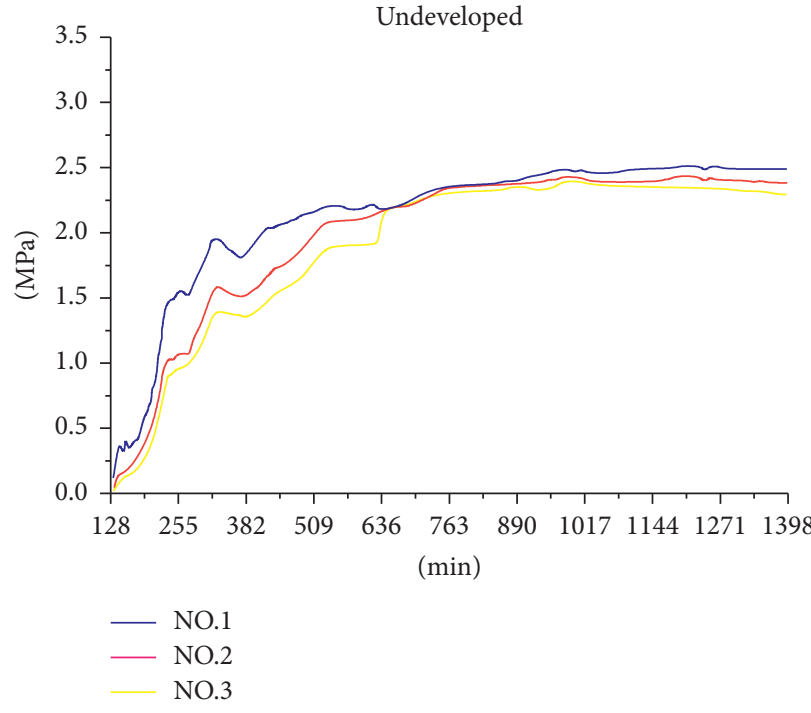

(a)

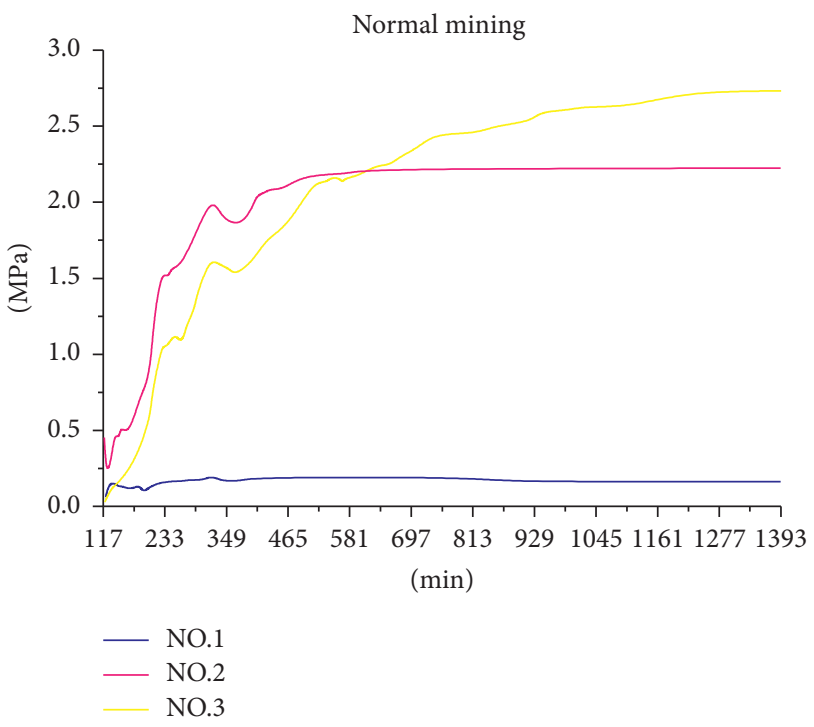

(b)

Figure 10: Continued. 


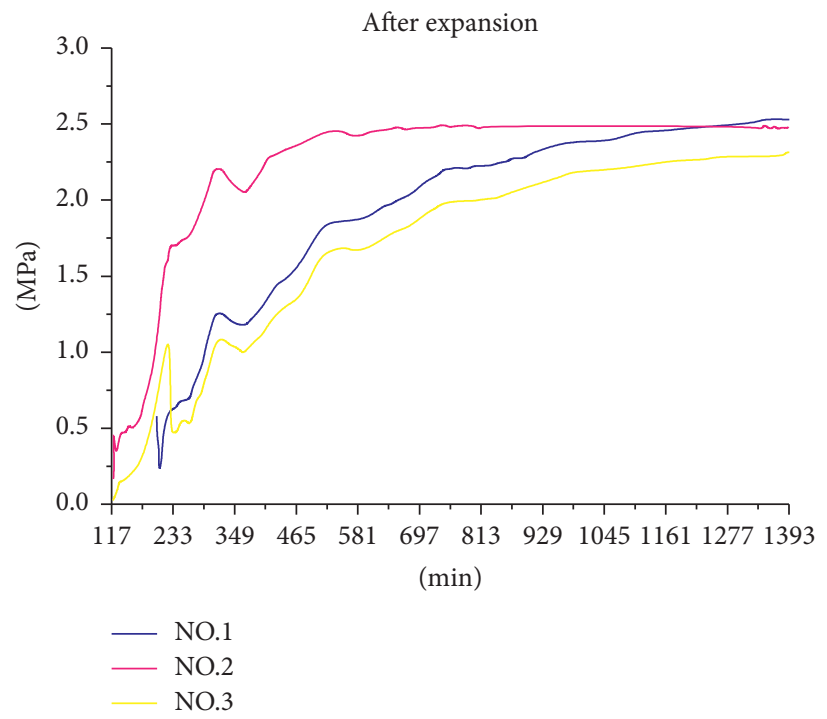

(c)

FIGURE 10: Stress variation of three measuring points under three states: (a) stress variation diagram of three measuring points at the top corner of the roadway before mining; (b) stress variation diagram of three measuring points at the top angle of the roadway end in normal mining; (c) stress variation diagram of three measuring points at the top corner of the end in mining after cutting and reinforcement of the anchor cable.

transferred to the deep rock, and the surrounding rock at the top corner of the end tends to be stable.

(iii) Figure 9(c) shows that the stress concentration of the top corner at the end of the working face at measuring point 3 reaches $31.5 \mathrm{MPa}$ without mining and with normal mining, which is gradually reduced compared with measuring point 2. However, because of mining, rib spalling and roof fall accidents are prone to occur. Compared with the stress of measuring point 1 and measuring point 3 , the stress at measuring point 3 increases gradually after cutting and reinforcing the anchor cable. Cable reinforcement releases the stress concentration area at the top corner of the end, transfers the stress to the deep rock, and controls the surrounding rock at the top corner of the end.

(2) The stresses of the surrounding rock at measuring points 1,2, and 3 of the second monitoring station were compared and analyzed when the working face was not mined, mined, and mined after cutting and reinforcing with an anchor cable, as shown in Figure 10.

(i) Figure 10(a) shows that the stress of measuring points 1,2 , and 3 at the top corner of the end decreases gradually without mining. The stress concentration area is formed at measuring point 1 , and the surrounding rock stress at measuring point 1 is the highest, close to $28.9 \mathrm{MPa}$, which is in a critical state. At $28.9 \mathrm{MPa}$, mining of the working face is prone to spalling and roof fall accidents. (ii) Figure 10(b) shows that, compared with no mining, the stresses at measuring points 1 and 2 at the top corner of the end have been greatly reduced, indicating that spalling and roof fall accidents may occur at the working face. The stress concentration area is released, and the stress at measuring point 3 exceeds $32.3 \mathrm{MPa}$, indicating that the spalling and roof fall accidents continue to expand to the deep rock.

(iii) Figure 10(c) shows that when mining is carried out after cutting and reinforcing the anchor cable, the stress values of measuring points 1,2 , and 3 are all within $26.1 \mathrm{MPa}$, and the stress area is relatively concentrated. The stress concentration area of the measuring point around the top corner of the end is released to a certain extent, and there are no spalling or roof fall accidents, so the top corner of the end is controlled during mining.

\section{Conclusions}

Elastic-plastic mechanics, complex variable function theory, and Mathcad 14 software were used to analyze the stress of surrounding rocks at the top corner of the end. FLAC3D numerical simulation software was used to analyze the stress change of surrounding rocks and the failure of the plastic zone at the top corner of the end before and after the mining of a fully mechanized caving face. With the model, we simulate the evolution process of the failure mechanism of surrounding rocks at the top corner of the end.

The stress of roadway surrounding rocks under unequal lateral pressure is analyzed using elastic-plastic mechanics, 
complex variable function theory, and Mathcad 14 software. It is concluded that the stress concentration area of roadway surrounding rocks is at the top and bottom corner of the roadway, and the maximum stress value is close to $30 \mathrm{MPa}$. We analyzed the influence of lateral pressure coefficient on roadway stress. The stress of the roadway increases with the increment of lateral pressure coefficient.

FLAC3D numerical simulation and field monitoring of the KSE-II-1 borehole stress meter were carried out using the failure evolution process of surrounding rocks at the top corner of a fully mechanized caving face. It is concluded that the stress of surrounding rocks is $28.9 \mathrm{MPa}$ when the top corner of the end is stable, and the stress of surrounding rocks is $32.3 \mathrm{MPa}$ when the rib spalling and roof fall occur under the influence of mining.

The stress distribution of the top corner of the end is changed after cutting and reinforcing the anchor cable, and the original stress concentration area is released and transferred to the deep rock. Under the influence of mining, the surrounding rock stress at the top corner of the end is maintained at $26.1 \mathrm{MPa}$, which is in a stable state.

\section{Data Availability}

The data used to support the findings of this study are available from the corresponding author upon request.

\section{Conflicts of Interest}

The authors declare that they have no conflicts of interest.

\section{Acknowledgments}

This work was supported by Scientific and Technological Innovation Programs of Higher Education Institutions in ShanxiShanxi (2020L0724) and the Engineering Laboratory of Deep Mine Rockburst Disaster Assessment Open Project (LMYK2021009).

\section{References}

[1] Y. Z. Wu, "Stabilization principle and technique control of face-end support at fully-mechanized coal caving face," Coal, vol. 9, no. 107, pp. 25-28, 2008.

[2] H. Basarir, I. Ferid Oge, and O. Aydin, "Prediction of the stresses around main and tail gates during top coal caving by 3D numerical analysis," International Journal of Rock Mechanics and Mining Sciences, vol. 76, pp. 88-97, 2015.

[3] G. Jeromel, M. Medved, and J. Likar, "An analysis of the geomechanical processes in coal mining using the Velenje mining method," Acta Geotechnica Slovenica, vol. 7, pp. 31-45, 2010.

[4] C. W. Zang, J. F. Xia, H. C. Li, and J. G. Zhu, "Study on rational support strength of roof at face-end area of fully mechanized caving face," Safety In Coal Mines, vol. 46, no. 6, pp. 50-53, 2015.

[5] D. Z. Kong, W. Jiang, Y. Chen, Z. Song, and Z. Ma, "Study of roof stability of the end of working face in upward longwall top coal," Arabian Journal of Geosciences, vol. 10, pp. 184-194, 2017.

[6] M. Khanal, D. Adhikary, and R. Balusu, "Prefeasibility study-geotechnical studies for introducing longwall top coal caving in Indian mines," Journal of Mining Science, vol. 50, no. 4, pp. 719-732, 2014.

[7] J. Likar, M. Medved, M. Lenart, V. Malenković, G. Jeromel, and E. Dervarič, "Analysis of geomechanical changes in hanging wall caused by longwall multi top caving in coal mining," Journal of Mining Science, vol. 48, pp. 135-145, 2012.

[8] W. Lawrence, "A method for the design of longwall gateroad roof support," International Journal of Rock Mechanics and Mining Sciences, vol. 46, pp. 789-795, 2004.

[9] T. Jin, K. X. Zhang, Z. Y. Qin, and M. G. Fan, "Stability analysis and control of face end in fully-mechanized coal winning face," Coal Technology, vol. 11, pp. 29-32, 2015.

[10] Z. J. Liu, "Analysis and control of falling and leaking mechanism of broken roof end," Energy AND Energy Conservation, vol. 11, pp. 172-173, 2015.

[11] S. C. Li, S. C. Zhuo, and W. H. Xie, "Natural boundary element method for the stress field of circular roadway's surrounding rocks," Journal of China Coal Society, vol. 29, no. 6, pp. 672-675, 2004.

[12] X. B. Wang, Y. S. Pan, and Y. J. Li, "Effect of confining pressure on distributions of horizontal and vertical stresses around rectangular roadway and broken rock zone," Chinese Journal of Underground Space and Engineering, vol. 2, no. 6, pp. 962-970, 2006.

[13] M. Y. Fattah, M. J. Hamoud, F. A. Salman, and A. Raheem, "Complex variable solution of elastic tunneling problems," International Journal of the Physical Sciences, vol. 5, no. 13, pp. 1999-2013, 2010.

[14] N. I. Muskhelishvili, Some Basic Problems of Mathematical Theory of Elasticity, Noordhoff, Groningen, The Netherlands, 2nd edition, 1963.

[15] L. Yuan, Z. N. Gao, and X. R. Meng, "Viscoelastic analysis of stress concentration coefficient in rectangular roadway based on complex variable function," Safety In Coal Mines, vol. 44, no. 2, pp. 196-199, 2013.

[16] R. F. Wang, K. X. Zhang, W. L. Shen, and H. Cui, "Research on grouting strengthening in control of stress concentration in deep tunnel surrounding rocks," Coal Technology, vol. 35, no. 1, pp. 65-68, 2016.

[17] A. Bobet, "Drained and undrained response of deep tunnels subjected to far-field shearloading," Tunnelling and Underground Space Technology, vol. 25, pp. 21-31, 2010.

[18] G. S. Zheng, MATHCAD2000 Practical Tutorial, National Defense Industry Press, Beijing, China, 2000.

[19] D. Y. Chen, Numberical Simulation on Pre-stressed Bolt Support of Underground Project, Shandong University of Science and Technology, Qingdao, China, 2005.

[20] Y. Wu, Research on the Roadway Support under the Influence of Mining, Inner Mongolia University of Science and Technology, Baotou, China, 2015.

[21] L. Tian, "Simulation analysis of FLAC3D in support of numerical tunnel," Inner Mongolia Coal Economy, vol. 1, pp. 92-97, 2014.

[22] Q. B. Meng, L. J. Han, W. G. Qiao, D. G. Lin, and L. C. Wei, "Numerical simulation of cross-section shape optimization design of deep soft rock roadway under high stress," Journal of Mining and Safety Engineering, vol. 29, no. 5, pp. 650-656, 2012.

[23] Y. G. Gao, Study on Rapid Modeling Method of FLAC3D Model Based on AutoCAD File, Xi'an University of Science and Technology, Xi'an, China, 2012.

[24] Y. H. Shan, Q. Y. Shang, L. K. Xie, and G. Guo, "Numerical simulation on deep laneway surrounding rocks deformation based on FLAC3D," Morden Mining, vol. 517, pp. 28-29, 2012. 
[25] D. Lin, Y. Yang, C. H. Wang, and G. R. Xu, "Pressure behavior and analysis of rock damage in roadway by the first mining based on FLAC3D simulation," Science Technology and Engineering, vol. 11, no. 15, pp. 3407-3412, 2011.

[26] P. R. Dawson and D. E. Munson, "Numerical simulation of creep deformations around a room in a deep potash mine," International Journal of Rock Mechanics and Mining Sciences, vol. 20, no. 1, pp. 33-42, 1983.

[27] M. Xiao, D. X. Ding, and Y. G. Mo, "Numerical simulation of surrounding rocks stability of soft rock roadway based on FLAC3D," Mining R \& D, vol. 27, no. 1, pp. 73-75, 2007.

[28] Z. Zhang, M. Deng, X. Wang, W. Yu, F. Zhang, and V. D. Dao, "Field and numerical investigations on the lower coal seam entry failure analysis under the remnant pillar," Engineering Failure Analysis, vol. 115, 2020.

[29] Z. Zhang, M. Deng, J. Bai, S. Yan, and X. Y. Yu, "Stability control of gob-side entry retained under the gob with close distance coal seams," International Journal of Mining Science and Technology, vol. 31, no. 2, pp. 321-332, 2020. 